
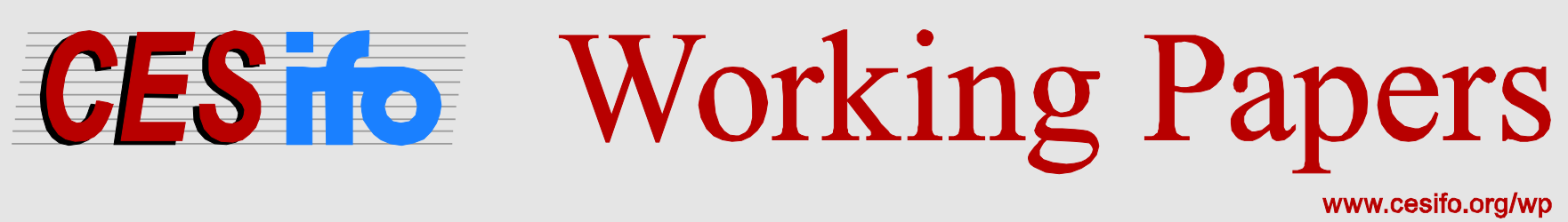

\title{
Tax Evasion in a Cournot Oligopoly with Endogenous Entry
}

\author{
Laszlo Goerke
}

CESIFO WORKING PAPER NO. 6239

CATEgORY 1: PUBlic FinANCE

DeCEMBER 2016

An electronic version of the paper may be downloaded

- from the SSRN website:

- from the RePEc website:

- from the CESifo website:

wWw.SSRN.com

Www.RePEc.org

www.CESifo-group.org/wp

\section{CESifo}




\title{
Tax Evasion in a Cournot Oligopoly with Endogenous Entry
}

\begin{abstract}
If an additional competitor reduces output per firm in a homogenous Cournot-oligopoly, market entry will be excessive. Taxes can correct the so-called business stealing externality. We investigate how evading a tax on operating profits affects the excessive entry prediction. Tax evasion raises the number of firms in market equilibrium and can alter their welfare-maximizing number. In consequence, evasion can aggravate or mitigate excessive entry. Which of these outcomes prevails is determined by the direct welfare consequences of tax evasion and the relationship between evasion and the tax base. We also determine conditions which imply that overall welfare declines with tax evasion.
\end{abstract}

JEL-Codes: D430, H260, L130.

Keywords: endogenous entry, oligopoly, tax evasion, welfare.

\author{
Laszlo Goerke \\ Institute for Labour Law and Industrial Relations \\ in the European Union / Trier University \\ Campus II \\ Germany-54286 Trier \\ goerke@iaaeu.de
}

02.12.2016

I am grateful for comments on earlier versions of this paper by Marco de Pinto, Tim Friehe as well as workshop and seminar participants in Brescia, Darmstadt, Marburg and Trier. Moreover, I have received very constructive suggestions by two anonymous referees which have greatly helped to improve the paper. 


\section{Introduction}

Markets for many consumption goods, such as cars, food, beverages, communication devices and banking services, are characterised by oligopolistic structures. Competition between firms in these markets is often fierce and companies frequently seem to resort to illegal or semilegal activities in order to raise profits. Tax shifting, tax avoidance or even outright evasion, corruption and the violation of labour and environmental standards represent instances of such behaviour. The relevance of such activities is demonstrated by legal activities to decrease their impact. The Council of the European Union, for example, agreed on a proposal to reduce profit-shifting of multinational companies to low tax countries in order to reduce avoidance activities (see European Commission 2016). A further example of such attempts in the banking sector recently attracted substantial political attention in Germany. The national parliament set up a committee to investigate how banks used dividend stripping to create multiple entitlements to tax refunds and how the tax administration enabled such activities (Bundestag 2016).

In this paper, we focus on the evasion of taxes and take into account that the number of competitors is not given exogenously, but determined endogenously by a profit constraint. We focus on a particular analytical set-up, namely a Cournot oligopoly for a homogenous good. Access to this oligopoly is feasible, but costly. Our starting point is the well-established insight that the incentives to enter such an oligopoly are likely to be excessive. This will be the case if an increase in the number of competitors reduces output per firm (the so-called business stealing effect; see, inter alia, Mankiw and Whinston 1986, Varian 1995 and Amir et al. 2014). The intuition is that an entrant will only take into account the impact on its own payoff, but neglect that output of other firms is affected. Since each competitor pays up-front costs, in order to gain access to the market, the output externality affects welfare via entry decisions. While the robustness of the so-called excess entry theorem has been looked at from a variety of perspectives, its policy implications seem to be straightforward and have not found a comparable degree of attention. This is noteworthy because the inefficiencies associated with (1) oligopolistic market structures and (2) externalities due to entry decisions provide ample scope for regulatory interventions. Such regulations, in turn, make feasible tax evasion and avoidance activities such as those mentioned above.

We suppose that firms pay a tax on operating profits. Such a tax has an immediate impact on the number of entrants because it lowers net profits. However, it does not directly alter output decisions, which are distorted due to market power. For an exogenously given tax rate, we 
enquire whether tax evasion makes excess entry more or less likely. Further, we analyse the welfare effects of evasion because they are not solely due to a change in the number of firms. At first sight, the effect of tax evasion appears to be obvious. It will only be undertaken if profits increase which, in turn, makes market entry more attractive. Consequently, tax evasion is likely to aggravate excess entry of firms, as conjectured by Goerke and Runkel (2006). Our analysis indeed shows that tax evasion increases the number of firms in market equilibrium. However, we show that this line of argument does not necessarily provide information about excessive entry, in contrast to the above conjecture. This is the case because tax evasion may alter the welfare-maximising number of firms. Hence, the impact on the benchmark which is used to evaluate the market outcome has to be taken in account, as well. Our next result relates to this benchmark. If tax evasion is resource-intensive, the welfare-maximising number of firms varies with evasion. In particular, if a decrease in the tax base due to more firms also lowers evasion activities per firm, more competitors may reduce the welfare costs of tax evasion. Accordingly, the welfare-maximising number of competitors increases with tax evasion. Thus, the impact of tax evasion on excessive entry will be ambiguous. We provide an example showing that excessive entry can actually decline. If however, a lower tax base raises evasion activities, tax evasion will reduce the welfare-maximising number of competitors and excessive entry will become more pronounced.

Our contribution is primarily related to the literature on excessive entry in Cournot oligopolies for homogenous goods and the impact of taxation in such markets. The prediction that entry into an oligopoly may be excessive has initially been established by, inter alia, von Weizsäcker (1980), Perry (1984), Mankiw and Whinston (1986), and Suzumura and Kiyono (1987). The suitability of taxes to deter entry has not been looked at intensively. Mankiw and Whinston (1986), for example, only mention in passing a tax as an illustration of an entry fee. Ohkawa and Okamura (2003) show that a lump-sum tax can be used to attain the second-best optimal number of firms. Konishi et al. (1990) and Suzumura (1995) consider balancedbudget tax reforms in a setting in which firms use capital and labour as inputs. One of the main results is that a welfare improving reform generally involves lump-sum taxation. Finally, Hamilton (1999) demonstrates that a single tax can induce (first-best) welfaremaximising output and entry decisions. This tax per unit of output consists of the difference between the producer price in market equilibrium and the producer price which a social planner would set. Since welfare will be maximal if firms base their output and entry choices on the outcome which would result in a perfectly competitive setting, the welfare-maximising tax effectively ensures that the competitive after-tax price governs firm behaviour. 
Taxes have also been looked at in symmetric oligopoly settings with free entry from other perspectives. These contributions, for example, focus on the extent to which taxes can be shifted forward and affect output (cf. Stern 1987 and Besley 1989) or the comparison between ad valorem and specific taxes (Delipalla and Keen 1992). Accordingly, the analyses do not look at the impact of taxation on excessive entry. Goerke and Runkel (2011) investigate how an exogenous change in the intensity of competition affects evasion of a sales tax. Their basic idea is that tax evasion alters the market outcome and, hence, the welfare consequences of entry. This notion constitutes one starting point of the present study, as well.

Finally, there are contributions which focus on other types of illegal behaviour, such as corruption. Amir and Burr (2015) and Seidel and Thum (2016) both assume that production is feasible only if firms bribe officials to allow them to enter the market. Amir and Burr (2015) analyse a Cournot oligopoly and, inter alia, demonstrate that corruption tends to deter entry. Moreover, competition among corrupt officials may result in optimal entry, assuming that bribes redistribute income. Seidel and Thum (2016) additionally consider tax evasion but without the possibility of excessive entry. Moreover, they do not explicitly model the product market. Seidel and Thum (2016) show that tax evasion raises the number of competitors if it weakens the detrimental impact of bribery on entry.

In the further course of the paper, in Section 2 we set out the model and characterise the market equilibrium as well as the welfare maximum. In Section 3, we consider the relation between tax evasion and excessive entry, while in Section 4 the welfare consequences of evasion are derived at. In Section 5, we provide a numerical example, based on a linear inverse demand curve, to illustrate the previous findings. Section 6 concludes.

\section{Analytical Framework}

\subsection{Model}

We consider a market for a homogeneous good in which $\mathrm{n}$ profit-maximising firms compete in quantities, taking as given output choices of other firms (Cournot-Nash behaviour). Gross operating profits of firm $\mathrm{j}, \mathrm{j}=1, . ., \mathrm{n}$, consist of the difference between revenues and production costs. Revenues are given by the product of the price, $\mathrm{P}(\mathrm{X})$, and output, $\mathrm{x}_{\mathrm{j}}$, of firm $\mathrm{j}$, where $\mathrm{X}$ denotes aggregate output and equals the sum of $\mathrm{x}_{\mathrm{j}}$ and output of all other firms, $X_{-j}, X:=x_{j}+X_{-j}$, and $P(X)$ is the inverse demand curve. The price is decreasing in aggregate output, such that $\mathrm{P}^{\prime}(\mathrm{X})<0$. For later use, we define the elasticity of the slope of the 
(inverse) demand curve, $\mathrm{P}(\mathrm{X})$, as $\eta:=\mathrm{P}^{\prime \prime}(\mathrm{X}) \mathrm{X} / \mathrm{P}^{\prime}(\mathrm{X})$. Given linear production costs, $\mathrm{cx}_{\mathrm{j}}, \mathrm{c}>0$, gross operating profits of firm $\mathrm{j}$ are:

$$
\pi_{j}=P\left(x_{j}+X_{-j}\right) x_{j}-c x_{j}
$$

These operating profits are subject to a linear tax at rate $\tau, 0<\tau<1$. The resulting tax obligation can be lowered by evasion or avoidance activities. Given risk neutrality, the distinction between (illegal) evasion and (legal) avoidance activities is without analytical consequences and for simplicity we focus on tax evasion.

Evading a fraction $\alpha_{j}, 0 \leq \alpha_{j}<1$, of taxes due reduces payments by an amount $\tau \alpha_{j} \pi_{j}$ and causes expected costs of evasion, $\mathrm{T}$. We specify the costs of evasion in a very general manner as $\mathrm{T}\left(\alpha_{\mathrm{j}}, \pi_{\mathrm{j}}\right)=\mathrm{qS}\left(\alpha_{\mathrm{j}}, \pi_{\mathrm{j}}\right)+\mathrm{c}_{\mathrm{fix}} \mathrm{I}, 0<\mathrm{q}<1$, where $\mathrm{q}$ can be interpreted as probability of being detected evading taxes, $I$ is an indicator variable that equals one if $\alpha_{j}$ is positive and zero otherwise, and $c_{f i x}, c_{f i x} \geq 0$, represent fixed costs of tax evasion. Further, we assume $S\left(0, \pi_{j}\right)$ $=0$ and that the costs of evasion, $\mathrm{S}$, are increasing in the fraction, $\alpha_{j}$, of the tax burden evaded at an increasing rate, implying that $\mathrm{S}_{1}, \mathrm{~S}_{11}>0$ hold, where subscripts denote partial derivatives. ${ }^{1}$ If fine payments constitute the costs of tax evasion, $S\left(\alpha_{j}, \pi_{j}\right)$ is likely to increase with the tax base, $\pi_{j}$, as well, such that $S_{2}>0$ applies. It is also conceivable that a greater tax base opens up better opportunities for tax evasion. In consequence, it would become less costly to evade taxes such that $\mathrm{S}_{2}<0$ holds true. A special case often looked at is that $\mathrm{S}$ is a function of the undeclared tax base, i. e., that $S\left(\alpha_{j}, \pi_{j}\right)=S\left(\alpha_{j} \pi_{j}\right)$. This specification, furthermore, implies that $S_{1} \alpha_{j}=S_{2} \pi_{j}>0$ and $S_{12}>0$. However, it may well be the case that raising the fraction of taxes not paid, $\alpha_{j}$, becomes cheaper, the higher the tax base, $\pi_{j}$, is. Accordingly, $\mathrm{S}_{12}<0$ would represent an appropriate description of evasion technologies. ${ }^{2}$ Therefore, following Roine (2006), Traxler (2009) and Goerke (2012), for example, we do not impose a sign on $\mathrm{S}_{12}{ }^{3}$

\footnotetext{
${ }^{1}$ See, for example, Cremer and Gahvari (1993) and Besfamille et al. (2009, 2013) for similar approaches. In contrast to these contributions, we do not assume $\mathrm{S}_{1}(0, \pi)=0$ to also allow for the possibility that no evasion constitutes optimal behaviour.

${ }^{2}$ See Slemrod (2001) and Grubert and Slemrod (1998) for models of personal or corporate income tax avoidance which are based on assumptions which are tantamount to $\mathrm{S}_{12}<0$.

${ }^{3}$ Note that the costs of evasion could also be specified as increasing with the tax rate, $\tau$. For a given tax rate, such modification would not alter the main findings because the alteration would primarily affect the impact of the tax rate on evasion activities (see Appendix A.1 below).
} 
In order to produce, a firm has to enter the market at cost $K, K>0$. Since operating profits constitute the tax base, entry costs are not tax deductible. This ensures that the tax affects market entry. After-tax profits, $\Pi_{j}$, hence, equal:

$$
\Pi_{j}=\left(1-\tau\left(1-\alpha_{j}\right)\right) \underbrace{\left[P\left(x_{j}+X_{-j}\right) x_{j}-c x_{j}\right]}_{=\pi_{j}}-K-T\left(\alpha_{j}, \pi_{j}\right)
$$

We assume that after-tax profits, $\Pi_{j}$, increase with operating profits, $\pi_{\mathrm{j}}$, implying that $1-\tau(1$ $\left.-\alpha_{j}\right)-T_{2}\left(\alpha_{j}, \pi_{j}\right)>0$ holds. As shown below, this restriction together with a negative impact of the number of firms on after-tax profits, i. e., $\mathrm{d}_{\mathrm{j}} / \mathrm{dn}<0$, guarantees stability of the equilibrium.

The structure of the game is as follows: In the first stage, a firm decides whether to access the market, paying up-front market entry costs, K. The firm correctly anticipates the equilibrium number of entrants and the decisions regarding output and tax evasion. In stage two, each firm determines output and the fraction of unpaid taxes simultaneously, taking as given the choices of the other entrants (Cournot-Nash-behaviour). The model is solved by backward induction. As usual in the literature on excessive entry, we ignore the integer constraint and treat the number of firms, n, as a continuous variable (cf. Seade 1980, Delipalla and Keen 1992, Hamilton 1999, inter alia).

\subsection{Market Outcome}

Assume that firms have decided about entry, Therefore, the number of firms, n, is given. Firm $\mathrm{j}$ maximizes profits with respect to its output, $\mathrm{x}_{\mathbf{j}}$, and the fraction of tax payments not remitted, $\alpha_{\mathrm{j}}$. This yields as first-order conditions:

$$
\begin{gathered}
\frac{\partial \Pi_{j}}{\partial x_{j}}=\left(1-\tau\left(1-\alpha_{j}\right)-T_{2}\left(\alpha_{j}, \pi_{j}\right)\right) \times\left[P^{\prime}\left(x_{j}+X_{-j}\right) x_{j}+P\left(x_{j}+X_{-j}\right)-c\right]=0 \\
\frac{\partial \Pi_{j}}{\partial \alpha_{j}}=\tau\left(P\left(x_{j}+X_{-j}\right)-c\right) x_{j}-T_{1}\left(\alpha_{j}, \pi_{j}\right)=0
\end{gathered}
$$

Equation (3a) shows that the restriction $1-\tau\left(1-\alpha_{j}\right)-T_{2}\left(\alpha_{j}, \pi_{j}\right)>0$ also guarantees a standard feature of models of tax evasion by firms, namely that the profit-maximising output level, $x_{j}$, is unaffected by the extent of tax evasion (cf. Yaniv 1995). The optimal fraction of tax payments evaded, $\alpha_{\mathrm{j}}$, balances the gain in terms of lower transfers to fiscal authorities, which depend on the tax rate and tax base, with the marginal costs of evasion. 
If $\tau(\mathrm{P}(\mathrm{X})-\mathrm{c}) \mathrm{x}_{\mathrm{j}}<\mathrm{T}_{1}\left(0, \pi_{\mathrm{j}}\right)$ holds, the firm $\mathrm{j}$ will refrain from evading taxes. Such a situation can arise if, for example, the fixed costs of tax evasion are sufficiently high. Given the separability of output and evasion choices, the firm's optimal output decision in the absence of tax evasion continues to be determined by equation ( $3 \mathrm{a})$, setting $\alpha_{\mathrm{j}}=\mathrm{T}_{2}=0$.

The second-order conditions for a maximum of (2) are:

$$
\begin{gathered}
\frac{\partial^{2} \Pi_{j}}{\partial\left(x_{j}\right)^{2}}=\left(1-\tau\left(1-\alpha_{j}\right)-T_{2}\left(\alpha_{j}, \pi_{j}\right)\right)\left[P^{\prime \prime}\left(x_{j}+X_{-j}\right) x_{j}+2 P^{\prime}\left(x_{j}+X_{-j}\right)\right]<0 \\
\frac{\partial^{2} \Pi_{j}}{\partial\left(\alpha_{j}\right)^{2}}=-T_{11}\left(\alpha_{j}, \pi_{j}\right)<0 \\
\frac{\partial^{2} \Pi_{j}}{\partial\left(x_{j}\right)^{2}} \frac{\partial^{2} \Pi_{j}}{\partial\left(\alpha_{j}\right)^{2}}-\left(\frac{\partial^{2} \Pi_{j}}{\partial x_{j} \partial \alpha_{j}}\right)^{2}=\frac{\partial^{2} \Pi_{j}}{\partial\left(x_{j}\right)^{2}} \frac{\partial^{2} \Pi_{j}}{\partial\left(\alpha_{j}\right)^{2}}>0
\end{gathered}
$$

Equations (4a) and (4b), respectively, show that profits are strictly concave in output and evasion choices. (4c) then clarifies that the firm's optimisation problem is well-behaved and that interior choices of output, $x_{j}>0$, and the fraction of the tax burden evaded, $0<\alpha_{j}<1$, define a unique profit-maximum. Since profits decline with the number of firms, as will be shown below, firms enter the market until profits are zero.

We subsequently assume that all firms behave identically, such that the ensuing equilibrium is symmetric and aggregate output, $X$, equals $X=n_{j}=n x .{ }^{4}$ Accordingly, we omit the subscript $\mathrm{j}$ from now on. Moreover, the term in square brackets in the second-order condition (4a) can, using $\eta:=\mathrm{P}^{\prime \prime}(\mathrm{X}) \mathrm{X} / \mathrm{P}^{\prime}(\mathrm{X})$, be rewritten as (see, Seade 1980 and Besley 1989, inter alia):

$$
\mathrm{P}^{\prime \prime}(\mathrm{x}+(\mathrm{n}-1) \mathrm{x}) \mathrm{x}+2 \mathrm{P}^{\prime}(\mathrm{x}+(\mathrm{n}-1) \mathrm{x})=\mathrm{P}^{\prime \prime}(\mathrm{X}) \mathrm{x}+2 \mathrm{P}^{\prime}(\mathrm{X})=\frac{\mathrm{P}^{\prime}(\mathrm{X})}{\mathrm{n}}(\eta+2 \mathrm{n})<0
$$

Summarising the above, the market equilibrium is described by equations (6), (7) and (8) in the presence of tax evasion $(\alpha>0)$ and by (6') and (7) in the absence of tax evasion $(\alpha=0)$.

$$
\begin{gathered}
\mathrm{B}:=(1-\tau(1-\alpha))(\mathrm{P}(\mathrm{X})-\mathrm{c}) \mathrm{x}-\mathrm{K}-\mathrm{T}(\alpha, \pi)=0 \\
\mathrm{~B}^{\prime}:=(1-\tau)(\mathrm{P}(\mathrm{X})-\mathrm{c}) \mathrm{x}-\mathrm{K}=0
\end{gathered}
$$

\footnotetext{
${ }^{4}$ It could be argued that tax evasion is easily detectable because all firms are ex-post identical and evade the same amount. Accordingly, authorities could eradicate evasion by auditing all firms. Such an outcome will not occur if either proving evasion activities is required and sufficiently costly to tax authorities such that they cannot establish illegal activities for all firms. Alternatively, one could assume that operating profits are given by $(\mathrm{P}(\mathrm{X})-\mathrm{c}) \mathrm{x}-\mathrm{k}$, where $\mathrm{k}$ varies across firms. If authorities do not know the value of $\mathrm{k}$, a given tax payment does no longer indicate illegal behaviour. Since the inclusion of such firm-specific operational costs would considerably extend the notation without yielding additional insights, we refrain from doing so.
} 


$$
\begin{aligned}
& A:=P^{\prime}(X) x+P(X)-c=0 \\
& E:=\tau(P(X)-c) x-T_{1}(\alpha, \pi)=0
\end{aligned}
$$

Equation (6) (equation (6')) describes the condition which determines the outcome of the first stage of the game, namely a firm's entry decision in the presence (absence) of tax evasion. Accordingly, the restriction determines the number of firms, that is, $\mathrm{n}^{+}\left(\mathrm{n}^{0}\right)$ if there is (no) evasion, for a given output level per firm and a given extent of tax evasion, since aggregate output, $\mathrm{X}^{+}=\mathrm{x}^{+} \mathrm{n}^{+}$or $\mathrm{X}^{0}=\mathrm{n}^{0} \mathrm{x}^{0}$, depends on the number of firms. Equations (7) and (8) describe the firms' optimal decisons in the second stage of the game if tax evasion takes place. More specifically, the former equation characterises a firm's output choice, for a given number of competitors. We denote it by $\mathrm{x}^{+}\left(\mathrm{x}^{0}\right)$ in the presence (absence) of tax evasion activities. Finally, equation (8) defines the optimal fraction of the tax burden evaded, for given levels of aggregate output, $\mathrm{X}^{+}$, and output per firm, $\mathrm{x}^{+}$. In the absence of evasion, the second stage of the game is described by equation (7) alone.

The derivatives of equations (6), (7) and (8) with respect to the endogenous variables are $A_{\alpha}$ $=\mathrm{B}_{\alpha}=0$ and, using the definition of $\eta$ in (10) and equation (7) in (11), furthermore, given by:

$$
\begin{gathered}
\mathrm{B}_{\mathrm{x}}=\left(1-\tau(1-\alpha)-\mathrm{T}_{2}(\alpha, \pi)\right) \mathrm{P}^{\prime}(\mathrm{X}) \mathrm{x}(\mathrm{n}-1)=\mathrm{B}_{\mathrm{n}} \frac{\mathrm{n}-1}{\mathrm{x}}<0 \\
\mathrm{~A}_{\mathrm{x}}=\mathrm{P}^{\prime}(\mathrm{X})(1+\mathrm{n}+\eta) \\
\mathrm{A}_{\mathrm{n}}=\mathrm{P}^{\prime}(\mathrm{X}) \frac{\mathrm{x}}{\mathrm{n}}(\mathrm{n}+\eta) \\
\mathrm{E}_{\mathrm{x}}=\mathrm{P}^{\prime}(\mathrm{X}) \mathrm{x}(\mathrm{n}-1)\left(\tau-\mathrm{T}_{12}(\alpha, \pi)\right)=\mathrm{E}_{\mathrm{n}} \frac{\mathrm{n}-1}{\mathrm{x}} \\
\mathrm{E}_{\alpha}=-\mathrm{T}_{11}(\alpha, \pi)<0
\end{gathered}
$$

Equation (9) shows the negative impact of a higher output and more competitors on the equilibrium level of after-tax profits. Equations (10) describe how a firm's output decision will be affected if all firms raise output marginally (see (10a)) or the number of competitors increases (cf. (10b)). Similarly, equations (11) clarify the consequences of such changes for a firm's evasion choices. Moreover, a higher level of operating profits will increase the fraction of taxes evaded, $\alpha$, ceteris paribus, if $\tau-\mathrm{T}_{12}>0$, since $\mathrm{d} \alpha / \mathrm{d} \pi=-\mathrm{E}_{\pi} / \mathrm{E}_{\alpha}$ and

$$
\mathrm{E}_{\pi}=\tau-\mathrm{T}_{12}(\alpha, \pi)
$$

Consequently, if the correlation between the tax base, $\pi$, and the fraction of taxes evaded, $\alpha$, is positive, tax evasion will become less attractive, ceteris paribus, as the output price declines, 
for example, because there are more competitors or output rises (cf. equation (11a)). The reason is that a lower price results in a fall in operating profits such that the gain from evading a given fraction of the tax burden imposed on these profits declines.

While it may appear plausible that more profitable firms evade more, in the present setting this will only be the case if $\mathrm{T}_{12}$ is negative or sufficiently small if positive. If, for example, $\mathrm{T}(\alpha, \pi)=\mathrm{T}(\alpha \pi), \mathrm{E}_{\pi}<0$ will hold and the above line of argument is reversed. Since there is no clear-cut empirical evidence on the relationship between tax evasion and the true tax base, we subsequently consider both $\mathrm{E}_{\boldsymbol{\pi}}>0$ and $\mathrm{E}_{\boldsymbol{\pi}}<0$.

If there is (no) tax evasion, the determinant of the system of equations describing the market equilibrium is labelled $\left(\mathrm{D}^{0}\right) \mathrm{D}^{+}$:

$$
D^{+}=E_{\alpha} D^{0}=E_{\alpha}\left[A_{x} B_{n}-B_{x} A_{n}\right]=\frac{E_{\alpha} B_{x} P^{\prime}(X) x(2 n+\eta)}{n(n-1)}<0
$$

For later use, it is helpful to consider a situation in which the number of competitors is not governed by the profit constraint (6) but determined exogenously, such that firms decide solely about output and tax evasion, and not about entry. The effects of an exogenous increase in the number of firms are:

$$
\begin{gathered}
\frac{d x}{d n}=-\frac{E_{\alpha} A_{n}}{E_{\alpha} A_{x}}=-\frac{x(n+\eta)}{n(1+n+\eta)} \\
\frac{d \alpha}{d n}=\frac{E_{x} A_{n}-E_{n} A_{x}}{E_{\alpha} A_{x}}=\frac{E_{\pi} P^{\prime}(X)(2 n+\eta) x^{2}}{T_{11}(\alpha, \pi) n(1+n+\eta)} \\
\frac{d \pi}{d n}=\left(P^{\prime}(X) n x+P(X)-c\right) \frac{d x}{d n}+P^{\prime}(X) x^{2} \\
=-P^{\prime}(X) x(n-1) \frac{x(n+\eta)}{n(1+n+\eta)}+P^{\prime}(X) x^{2}=\frac{P^{\prime}(X) x^{2}(2 n+\eta)}{n(1+n+\eta)}<0
\end{gathered}
$$

Using equation (13c), equilibrium after-tax profits, $\Pi$, can be shown to decline with the number of firms, $\mathrm{n}$, if $1-\tau(1-\alpha)-\mathrm{T}_{2}>0$, as indicated above. Consequently, the market equilibrium will be stable if additionally $1+n+\eta>0$ holds (cf. Seade 1980), which we assume to be the case. This restriction also guarantees the second-order condition (cf. equation (5)), as $1+n>2$ in oligopoly.

$$
\frac{\mathrm{d} \Pi}{\mathrm{dn}}=\left(1-\tau(1-\alpha)-\mathrm{T}_{2}(\alpha, \pi)\right) \frac{\mathrm{d} \pi}{\mathrm{dn}}<0
$$


Equation (13a) clarifies that the condition defining business stealing, namely that output per firm declines with their number $(n+\eta>0)$, is unaffected by tax evasion. The intuition is that output per firm does not vary with evasion activities, for a given number of competitors. More firms imply higher aggregate output. The resulting decrease in price and profits will lower (raise) the gain from tax evasion if there is a positive (negative) correlation between profits and the fraction of the tax burden evaded, i.e., if $\mathrm{E}_{\boldsymbol{\pi}}>(<) 0$, as clarified by equation (13b).

To complete the description of the market outcome, we may finally consider the impact of a variation in the tax rate. Since a firm's output choice is separable from its evasion choice and because profits decline with the tax rate, irrespective of whether there is tax evasion or not, the effects of the tax on output per firm and the number of firms are qualitatively unaffected by the extent of evasion. In particular, we show (see Appendix A.1) that a higher tax rate will raise output per firm if there is business stealing and reduce the number of firms and aggregate output. ${ }^{5}$ Moreover, evasion will surely rise with the tax rate if operating profits are correlated positively with the fraction of the tax burden evaded $\left(\mathrm{E}_{\pi}>0\right){ }^{6}$

\subsection{Welfare}

The prediction of excessive entry into an oligopolistic market is commonly derived by contrasting the market outcome with the second-best welfare maximum. ${ }^{7}$ This comparison is based on the notion that a firm's output decision cannot be determined by a social planner. This is also the approach we choose. If there is tax evasion in addition, fixing only the number of firms can result in a third-best outcome since evasion choices cannot be influenced directly by the welfare-maximising entity either. In order to avoid semantic imprecision, we subsequently refer to the welfare-maximising number of firms as second-best if there is no tax evasion and as constrained-optimal in the presence of evasion, as long as a distinction is required. Otherwise, we will simply speak of a constrained-optimal outcome.

\footnotetext{
${ }^{5}$ Besley (1989) considers a unit tax on output in a Cournot oligopoly in the absence of tax evasion. He shows for a setting with constant unit costs that output per firm rises with the tax rate if $\eta>0$, while the number of firms declines with the tax rate if $2+\eta>0$, while aggregate output unambiguously falls. Delipalla and Keen (1992) provide comparable predictions and, furthermore, show that the consequences of a higher ad valorem tax are more ambiguous because this tax also reduces marginal revenues and, thus, mitigates the product market imperfection (see also Stern 1987 and Hamilton 1999).

${ }^{6}$ The positive impact of the tax rate on tax evasion is a common prediction in models of tax evasion by firms which maximise (expected) profits (see, for example, Gahvari and Cremer 1993). If the objective is defined in terms of utility, risk aversion also plays a role (cf. Yaniv 1995, inter alia), as it is the case with regard to income taxes paid by individuals.

${ }^{7}$ von Weizsäcker (1980) and Suzumura and Kiyono (1987), for example, also compare the market outcome to the first-best.
} 
Welfare in the absence of taxation equals the sum of consumer surplus and profits. In our setting, tax revenues and the costs of tax evasion have to be incorporated additionally. While the firms' gains from evasion, i.e. lower tax payments, have no welfare effects because they reduce tax revenues by the same amount, the direct welfare impact of the firm's costs of evasion, $\mathrm{T}$, are less obvious. If, for example, tax evasion activities are costly because they require an unproductive use of resources, they will lower welfare per se (Seidel and Thum 2016). If, however, $\mathrm{T}$ represents monetary fines which lower profits but raise income of other agents in the economy or enhance tax revenues, the costs of evasion are welfare-neutral (Becker 1968). We capture these possibilities by introducing a parameter $\beta, 0 \leq \beta \leq 1$. If $\beta=0$ holds, costs of tax evasion T reduce welfare by their full amount. If $\beta=1$ applies, the costs of evasion are without immediate or direct welfare impact. Accordingly, for given values of $x$ and $\mathrm{n}$, welfare in the presence of tax evasion, $\mathrm{W}^{+}$, equals welfare in absence of evasion activities, $\mathrm{W}^{0}$, minus that part of the costs of evasion which directly reduces welfare:

$$
\begin{aligned}
\mathrm{W}^{+}(\mathrm{x}(\mathrm{n}), \mathrm{n})= & \int_{0}^{\mathrm{nx}} \mathrm{P}(\mathrm{s}) \mathrm{ds}-\mathrm{P}(\mathrm{X}) \mathrm{X}+[(1-\tau(1-\alpha))(\mathrm{P}(\mathrm{X})-\mathrm{c}) \mathrm{x}-\mathrm{K}-\mathrm{T}(\alpha(\mathrm{n}), \pi(\mathrm{n}))] \mathrm{n} \\
& \quad+\tau(1-\alpha)(\mathrm{P}(\mathrm{X})-\mathrm{c}) \mathrm{xn}+\beta \mathrm{T}(\alpha(\mathrm{n}), \pi(\mathrm{n})) \mathrm{n} \\
= & \int_{0}^{\mathrm{nx}} \mathrm{P}(\mathrm{s}) \mathrm{ds}-\mathrm{cxn}-\mathrm{Kn}-(1-\beta) \mathrm{T}(\alpha(\mathrm{n}), \pi(\mathrm{n})) \mathrm{n} \\
= & \mathrm{W}^{0}(\mathrm{x}, \mathrm{n})-(1-\beta) \mathrm{T}(\alpha(\mathrm{n}), \pi(\mathrm{n})) \mathrm{n}
\end{aligned}
$$

Equation (14) can also be interpreted as including at least implicitly the impact of changes in output, $\mathrm{x}$, and the number of firms, $\mathrm{n}$, on the government's costs of enforcing tax payments, i.e. of employing tax officials etc. If these costs are fixed and do not depend on the extent of tax evasion, they could simply be added to (14), but would not affect the maximisation of $\mathrm{W}^{+}$ with respect to $n$. If, however, an increase in tax evasion raises the costs of enforcement, this would be equivalent to $\beta<1$ because such costs are not born by firms but lower welfare. Therefore, an explicit incorporation of the costs of enforcement would make direct negative welfare consequences of tax evasion more likely.

Formally, the constrained-optimal number of firms is established by maximising welfare $\mathrm{W}^{+}$ with respect to the number of firms, subject to the firms' output and evasion choices and a given tax rate, i.e. $\mathrm{W}^{+}=\mathrm{W}^{+}(\mathrm{n}, \mathrm{x}(\mathrm{n}), \alpha(\mathrm{n}))$. Subsequently, the tax rate could be calculated which ensures that the desired number of firms enters the market. Alternatively, the welfaremaximising tax rate could be derived. Both approaches are equivalent. We will follow the 
first because it allows for more direct comparisons with the excess entry results derived in earlier contributions.

The second-best welfare-maximising number of firms in the absence of tax evasion and for a given tax rate is denoted by $\mathrm{n}^{0, \text { opt }}$ and implicitly defined by:

$$
\frac{d W^{0}}{d n}=\left(P\left(x^{0} n\right)-c\right) x^{0}-K+\left(P\left(x^{0} n\right)-c\right) n \frac{d x^{0}}{d n}=0
$$

Evaluating the derivative in (15) at that number of firms which ensures the zero-profit condition (6') in the absence of tax evasion, $\mathrm{n}^{0}$, yields:

$$
\frac{\mathrm{dW}}{\mathrm{dn}}_{\mid \mathrm{n}=\mathrm{n}^{0}}=\mathrm{K} \frac{\tau}{1-\tau}+\left(\mathrm{P}\left(\mathrm{X}^{0}\right)-\mathrm{c}\right) \mathrm{n}^{0} \frac{\mathrm{dx}}{\mathrm{dn}}
$$

If there is business stealing, i.e. $\mathrm{dx}^{0} / \mathrm{dn}<0$ holds, the second summand in (16) will be negative because the price exceeds marginal costs in the presence of market entry costs. In the absence of taxation, $\mathrm{dW}^{0} / \mathrm{dn}$ evaluated at $\mathrm{n}=\mathrm{n}^{0}$ is negative and we obtain the well-known excess entry result (see, inter alia, Mankiw and Whinston 1986, Suzumura and Kiyono 1987, and Varian 1995). The tax on operating profits mitigates the incentives to enter the market. ${ }^{8}$

Turning to a world with tax evasion activities, maximisation of $\mathrm{W}^{+}$with respect to $\mathrm{n}$, for a given tax rate, making use of (13a), and evaluating the derivative at the number of firms which ensures the zero-profit condition (6), $\mathrm{n}^{+}$, yields:

$$
\begin{array}{r}
\frac{\mathrm{dW}^{+}}{\mathrm{dn} \mid \mathrm{n}=\mathrm{n}^{+}}=\frac{\mathrm{K} \tau(1-\alpha)+\mathrm{T}(\alpha, \pi)}{1-\tau(1-\alpha)}+\left(\mathrm{P}\left(\mathrm{X}^{+}\right)-\mathrm{c}\right) \mathrm{n}^{+} \frac{\mathrm{dx}^{+}}{\mathrm{dn}} \\
-(1-\beta)\left[\mathrm{T}(\alpha, \pi)+\mathrm{n}^{+} \frac{\mathrm{dT}(\alpha, \pi)}{\mathrm{dn}}\right]
\end{array}
$$

Excess entry will be reduced by taxation of operating profits and the costs of evading this tax, as captured by the first term in (17). The higher is the fraction of taxes evaded, $\alpha$, the weaker the mitigating impact of taxation will be, ceteris paribus. This is the case because evasion effectively reduces the tax rate. Furthermore, if tax evasion has negative direct welfare effects $(\beta<1)$ and the costs of evasion decline with the number of firms, $\operatorname{dT}(\alpha, \pi) / \mathrm{dn}<0$, there is an additional channel through which the constrained-optimal number of firms is raised. Such effect occurs because firms do not take into account the welfare impact of a change in evasion

\footnotetext{
${ }^{8}$ Combining (13a) and (16), the tax rate which ensures the second-best optimal number of firms, $\mathrm{n}^{0, \text { opt }}$, can be calculated. It is implicitly defined by $\tau-\left(\mathrm{n}^{0, \text { opt }}(\tau)+\eta\right) /\left(1+\mathrm{n}^{0, \text { opt }}(\tau)+\eta\right)=0$.
} 
activities when deciding about entry, but only the immediate costs they incur themselves. ${ }^{9}$ Accordingly, $\beta<1$ creates a tax evasion externality.

\section{Tax Evasion and Entry}

Initially, we scrutinise how the number of firms in market equilibrium changes with tax evasion. Subsequently, we analyse whether the constrained-optimal quantity of firms in a setting with evasion activities differs from its second-best counterpart in a framework without evasion activities. The comparison of both alterations enables us to analyse the impact of tax evasion on the excess entry prediction.

While we derive our findings for a given tax rate, an alternative analytical approach to scrutinise the relationship between tax evasion and excessive entry would be to compare the welfare-maximising tax rates in a world without and a setting with tax evasion. While it is relatively straightforward to determine these rates if the firms' costs of tax evasion have no direct welfare effects, the approach is substantially more intricate if evasion has an immediate negative welfare impact. Consequently, we compare the number of firms.

\subsection{Tax Evasion and Entry in Market Equilibrium}

Because the number of firms in market equilibrium is determined by more than one condition (cf. equations (6), (7) and (8)), the change in the number of competitors can most straightforwardly be ascertained by investigating the effects of stronger incentives to evade taxes. In the present setting, tax evasion is likely to become more attractive (cf. equation (8)) if the detection probability declines. ${ }^{10}$ The consequences are summarised in

\footnotetext{
${ }^{9}$ As in a framework without evasion, the tax rate which ensures the constrained-optimal number of firms can be calculated on the basis of equations (7) and (17). For $\beta=1$, it is possible to show that the tax rate must satisfy $\tau(1$ $-\alpha)-\left(\mathrm{n}^{+, \text {opt }}(\tau)+\eta\right) /\left(1+\mathrm{n}^{+ \text {,opt }}(\tau)+\eta\right)<0$, where $\mathrm{n}^{0, \text { opt }}(\tau)=\mathrm{n}^{+ \text {opt }}(\tau)$ for any given tax rate and $\mathrm{dn} / \mathrm{d} \tau<0$. Hence, the constrained-optimal effective tax rate $\tau(1-\alpha)$ in the presence of evasion activities must be lower than the second-best optimal tax rate $\tau$ in a world without evasion. This is the case because the costs of evasion deter entry, ceteris paribus. For $\beta<1$, the optimal number of firms generally depends on the extent of tax evasion, such that the optimal tax rate cannot be defined straightforwardly.

${ }^{10}$ A lower detection probability combines a fall in the absolute costs of tax evasion with a decrease in marginal costs. An increase in tax evasion activities would also come about if either only the marginal costs of evasion decline, while the cost level is held constant, or alternatively if the absolute costs of evasion rise, while marginal costs remain unchanged. In terms of the model the first type of change would be equivalent to a reduction in the detection probability, $q$, and a rise in the fixed costs, $\mathrm{c}_{\mathrm{fix}}$, such that total costs $\mathrm{T}=\mathrm{q} \pi(\alpha, \alpha)+\mathrm{c}_{\mathrm{fix}}$ remain the same. The second type of change would be tantamount to a rise in the fixed costs. We do not explicitly consider the consequences of such alterations in the costs of tax evasion because they are more difficult to implement than
} 
Proposition 1: Tax Evasion and Entry in Market Equilibrium

Tax evasion increases the number of firms in market equilibrium.

\section{Proof: See Appendix A.2}

A lower detection probability has two effects on firm behaviour. First, it reduces the marginal costs of tax evasion (cf. equation (8)). This raises the fraction of the tax burden evaded. Second, it lowers the absolute (expected) costs of evasion and raises after-tax profits (cf. equation (6)). This effect on its own will mitigate (strengthen) the incentives to evade taxes if operating profits increase (decrease) the fraction of taxes evaded, i. e. if $\mathrm{E}_{\pi}>(<) 0 .{ }^{11}$ If the first, marginal effect and the second, level impact have opposite consequences with respect to evasion choices, the former will dominate the latter, for example, if the costs of tax evasion are a function of undeclared profits, i. e., if $\mathrm{T}(\alpha, \pi)=\mathrm{T}(\alpha \pi)$. Irrespective of the relationship between the detection probability, q, and tax evasion, a decline in q will lower the expected costs of tax evasion and increase expected profits. This profit level effect induces more firms to enter the market. Hence, an increase in evasion which arises, for example, because the detection probability declines, induces more firms to become Cournot competitors.

The findings summarised in Proposition 1 hold, independently of whether the initial level of tax evasion is positive or optimally zero. Therefore, Proposition 1 can be used to compare the market outcome in a setting with and without tax evasion. Consequently, it can be argued that tax evasion tends to aggravate excessive entry, as conjectured by Goerke and Runkel (2006). However, this statement implicitly presumes that the constrained-optimal number of firms remains the same. We now examine the implications of this assumption.

\subsection{Tax Evasion and the Constrained-optimal Number of Firms}

In order to compare the constrained welfare-maximizing number of firms in the presence of tax evasion to the second-best number in its absence, remember that for any given number of

a combined decrease in marginal and absolute costs. The relevant derivations can be obtained from the author upon request and are used to some extent to provide intuition for the results relating to a change in $\mathrm{q}$.

${ }^{11}$ If $\mathrm{E}_{\pi}>0$, higher profits imply that less evasion is needed to cover its costs, since the tax base rises. Accordingly, a fall in the absolute costs of evasion $\mathrm{T}$, holding constant the marginal costs, $\mathrm{T}^{\prime}$, results in less evasion.

$$
\frac{\mathrm{d} \alpha}{\mathrm{dT}}{ }_{\mid \mathrm{dT}^{\prime}=0}=-\mathrm{E}_{\pi} \frac{\left(\mathrm{P}^{\prime}(\mathrm{X}) \mathrm{x}\right)^{2}(2 \mathrm{n}+\eta)}{\mathrm{nD}^{+}}
$$

At the same time, higher profits induce more firms to enter the market. This implies that a fall solely in the cost level reduces evasion and enhances entry. 
firms output per firm, $\mathrm{x}$, will be unaffected by the existence of tax evasion $\left(\mathrm{x}=\mathrm{x}^{+}=\mathrm{x}^{0}\right.$; $\mathrm{cf}$. (7)). This implies that also aggregate output and the price will be the same. Taking the derivative of $\mathrm{W}^{+}=\mathrm{W}^{0}+(\beta-1) \mathrm{nT}(\alpha, \pi)$ (cf. equation (14)) with respect to $\mathrm{n}$, evaluating $\mathrm{dW}^{+} / \mathrm{dn}$ at $\mathrm{n}=\mathrm{n}^{0, \mathrm{opt}}$ (cf. (15)), and using equations (13b) and (13c) to obtain the first term including curly brackets, and further employing $\tau=\mathrm{T}_{1}(\alpha, \pi) / \pi$ and $\pi=(\mathrm{P}(\mathrm{X})-\mathrm{c}) \mathrm{x}=-\mathrm{P}^{\prime}(\mathrm{X}) \mathrm{x}^{2}$ from (1), (7), and (8), in order to derive the last equality below, yields:

$$
\begin{aligned}
& \frac{\mathrm{dW}^{+}}{\mathrm{dn} \mid \mathrm{n}=\mathrm{n}^{0, \mathrm{opt}}}=(\beta-1)\left[\mathrm{T}(\alpha, \pi)+\mathrm{n}^{0, \mathrm{opt}} \frac{\mathrm{dT}(\alpha(\mathrm{n}), \pi(\mathrm{n}))}{\mathrm{dn}}\right] \\
&=(\beta-1)\left[\mathrm{T}(\alpha, \pi)+\mathrm{n}^{0, \mathrm{opt}}\left(\mathrm{T}_{1}(\alpha, \pi) \frac{\mathrm{d} \alpha}{\mathrm{dn}}+\mathrm{T}_{2}(\alpha, \pi) \frac{\mathrm{d} \pi}{\mathrm{dn}}\right)\right] \\
&=(\beta-1)\left[\mathrm{T}(\alpha, \pi)+\frac{\mathrm{P}^{\prime}(\mathrm{X})\left(2 \mathrm{n}^{0, \mathrm{opt}}+\eta\right) \mathrm{x}^{2}}{1+\mathrm{n}^{0, \mathrm{opt}}+\eta}\left\{\frac{\mathrm{T}_{1}(\alpha, \pi) \mathrm{E}_{\pi}}{\mathrm{T}_{11}(\alpha, \pi)}+\mathrm{T}_{2}(\alpha, \pi)\right\}\right] \\
&=(\beta-1)\left[\mathrm{T}(\alpha, \pi)-\frac{2 \mathrm{n}^{0, \mathrm{opt}}+\eta}{1+\mathrm{n}^{0, \mathrm{opt}}+\eta}\left\{\frac{\left(\mathrm{T}_{1}(\alpha, \pi)\right)^{2}}{\mathrm{~T}_{11}(\alpha, \pi)}+\mathrm{T}_{2}(\alpha, \pi) \pi-\frac{\pi \mathrm{T}_{1}(\alpha, \pi) \mathrm{T}_{12}(\alpha, \pi)}{\mathrm{T}_{11}(\alpha, \pi)}\right\}\right]
\end{aligned}
$$

If tax evasion has no direct welfare effects $(\beta=1)$, it does not alter the welfare-maximising number of firms $\left(\mathrm{n}^{0, \mathrm{opt}}=\mathrm{n}^{+, \text {opt }}(\beta=1)\right)$. For $\beta<1, \mathrm{dW}^{+} / \mathrm{dn}$ evaluated at $\mathrm{n}=\mathrm{n}^{0, \text { opt }}$ will be positive if the term in square brackets in the last line of (18) is negative. Given strict concavity of $\mathrm{W}^{+}, \mathrm{dW}^{+} / \mathrm{dn}>0$ implies that $\mathrm{n}^{+, \text {opt }}(\beta=1)<\mathrm{n}^{+, \text {opt }}(\beta<1)$ and, hence, that $\mathrm{n}^{0, \mathrm{opt}}$ is smaller than $\mathrm{n}^{+ \text {,opt }}(\beta<1)$. Since $2 \mathrm{n}+\eta>1+\mathrm{n}+\eta$ for $\mathrm{n}>1$, a sufficient condition for $\mathrm{dW}^{+} / \mathrm{dn}$ $>0$ is that the term in curly brackets in the last line of (18) is weakly greater than $\mathrm{T}(\alpha, \pi)$. Proposition 2 summarises these considerations:

\section{Proposition 2: Tax Evasion and Constrained Welfare Optimum}

a) If tax evasion has no direct welfare effects $(\beta=1)$, it does not alter the constrained-optimal number of firms $\left(\mathrm{n}^{0, \mathrm{opt}}=\mathrm{n}^{+, \text {opt }}(\beta=1)\right)$.

b) Suppose, tax evasion has direct negative welfare consequences $(\beta<1)$ and the costs of tax evasion depend on the fraction of the tax base evaded only, $\mathrm{T}(\alpha, \pi)=$ $\mathrm{T}(\alpha, 0)$. If, additionally, costs of tax evasion are given by a second- or higherorder polynomial, and the fixed costs of tax evasion are not too high, tax evasion will raise the constrained-optimal number of firms, that is, $n^{+, \text {opt }}(\beta<1)>n^{0, o p t}$.

c) Suppose, tax evasion has direct negative welfare consequences $(\beta<1)$ and the costs of tax evasion are a function of undeclared profits, $\mathrm{T}(\alpha, \pi)=\mathrm{T}(\alpha \pi)$. Then, tax evasion reduces the constrained-optimal number of firms, that is, $\mathrm{n}^{+, \text {opt }}(\beta<1)$ $<\mathrm{n}^{0, \mathrm{opt}}$. 


\section{Proof: See Appendix A.3}

Suppose that the costs of tax evasion represent a pure transfer and, thus, reduce profits while they raise income of other agents by the same amount $(\beta=1)$. Consequently, the trade-off between the welfare-reducing increase in market entry costs due to more firms and the welfare-enhancing impact of higher aggregate output in the absence of tax evasion also applies in the presence of such activities. Therefore, the constrained-optimal number of firms will be unaffected by the opportunity to evade taxes.

If, however, the costs of evading taxes at least partially represent a loss in welfare $(\beta<1)$, there are additional and conflicting incentives to restrict entry. First, any firm entry which is avoided prevents this firm from evading taxes. This effect, as captured by the first term in square brackets in the last line of (18), unambiguously raises the gain from deterring entry. Second, a higher number of firms reduces tax evasion per firm $(\operatorname{dT}(\alpha, \pi) / \mathrm{dn}<0)$ if tax evasion is correlated positively with operating profits, i.e. if $\mathrm{E}_{\boldsymbol{\pi}}>0$, as evidenced by the penultimate line of equation (18). In consequence, there will be additional welfare gains from entry if $\mathrm{E}_{\boldsymbol{\pi}}>$ 0 . The net welfare effect due to (1) more firms evading taxes and (2) each firm evading less depends crucially on the fixed costs of evasion. If these costs are not too high, the impact of more firms will be relatively small. Given costs of tax evasion which depend on the fraction of the tax base evaded only, $\mathrm{T}(\alpha, \pi)=\mathrm{T}(\alpha, 0)$, it is then straightforward to specify a functional form for $\mathrm{T}$ such that the impact of more firms is dominated by less evasion per firm, such that tax evasion raises the constrained-optimal number of firms. If, however, tax evasion is correlated negatively with operating profits, i.e. if $\mathrm{E}_{\pi}<0$, the change in the costs of tax evasion per firm due to an increase in their number, i. e., $\mathrm{dT}(\alpha, \pi) / \mathrm{dn}$, becomes basically ambiguous. For the special case of costs of tax evasion which are a function of undeclared profits, $\mathrm{T}(\alpha, \pi)=\mathrm{T}(\alpha \pi)$, evasion per firm will not change with their number $(\mathrm{dT}(\alpha \pi) / \mathrm{dn}=0))$. Consequently, the welfare loss due to more firms evading taxes is not mitigated by a change in the costs of evasion per firm. Hence, the constrained-optimal number of firms falls.

\subsection{Tax Evasion and Excessive Entry}

In this section, we analyse how tax evasion affects the excessive entry result and, in particular, whether it aggravates of mitigates excessive entry. A natural question which then arises is how to define the optimal number of firms in the presence of tax evasion. One possibility would be to assume that the constrained-optimal number of firms is given by 
$\mathrm{n}^{0}$,opt, i.e. the number of competitors which maximises (second-best) welfare in the absence of tax evasion. This benchmark, however, ignores the costs of tax evasion which can alter the desirable number of firms. Therefore, we regard that number of firms as constrained-optimal which results when the welfare costs of tax evasion are incorporated, that is, the maximum of $\mathrm{W}^{+}$, as defined by $\mathrm{n}^{+}, \mathrm{opt}$ in equation (14). Excessive entry will be said to be aggravated, respectively mitigated, if the difference between the number of firms entering the market, $\mathrm{n}^{+}$, and the constrained-optimal figure, $\mathrm{n}^{+}, \mathrm{opt}$, rises, respectively, declines.

On the basis of these considerations, Propositions 1 and 2 can be combined to assess how tax evasion affects excess entry.

\section{Proposition 3: Tax Evasion and Excessive Entry}

a) Evasion of a given tax on operating profits aggravates excessive entry if either evasion has no direct welfare consequences $(\beta=1)$ or the direct welfare consequences are negative $(\beta<1)$ and the costs of tax evasion depend on the amount of undeclared taxes, $\mathrm{T}(\alpha, \pi)=\mathrm{T}(\alpha \pi)$, such that the optimal fraction, $\alpha$, of the tax burden evaded decreases with operating profits, i. e., $\mathrm{E}_{\pi}<0$.

b) Evasion of a given tax on operating profits may mitigate or aggravate excessive entry if evasion has direct negative welfare consequences $(\beta<1)$ and the optimal fraction, $\alpha$, of the tax burden evaded increases with operating profits, i. e., $\mathrm{E}_{\pi}>0$.

Proof: Follows from Propositions 1 and 2 and equation (18).

\section{Welfare Effects of Tax Evasion}

In the oligopoly model looked at, there are two sources of inefficiencies in the absence of tax evasion. One is due to the firms' quantity choices and the other resulting from entry decisions. In the presence of tax evasion, a third inefficiency can occur if tax evasion lowers welfare directly $(\beta<1)$. In order to analyse the overall welfare consequences of tax evasion, we again consider a decrease in the parameter $\mathrm{q}$.

\section{Proposition 4}

Starting from a situation of excessive entry, tax evasion will reduce welfare if

a) the direct welfare impact of evasion is zero $(\beta=1)$ or 
b) the immediate welfare impact of evasion is negative $(\beta<1)$ and $\left(\mathrm{S}_{1}(\alpha, \pi)\right)^{2}$ $\mathrm{S}(\alpha, \pi) \mathrm{S}_{11}(\alpha, \pi)>0$ holds.

\section{Proof: See Appendix A.4}

If there are no direct welfare effects of tax evasion $(\beta=1)$, the overall welfare consequences of tax evasion are solely due to the change in the number of firms. Consequently, welfare will decline if there are too many firms in the absence of tax evasion, because tax evasion raises the number of firms in market equilibrium (cf. Proposition 1). If the direct welfare impact of tax evasion is negative $(\beta<1)$, there are two additional effects. On the one hand, a lower detection probability promotes tax evasion which, in turn, decreases welfare, ceteris paribus. On the other hand, the decline in the detection probability reduces the direct welfare loss due to evasion. Therefore, tax evasion will surely diminish welfare if there are too many firms at the outset and the lower detection probability has relatively limited immediate welfare consequences. The condition stated in Proposition $4 b)$ ensures that $\partial \mathrm{W}^{+} / \partial \mathrm{q}=\mathrm{S}(\alpha, \pi)$ is not too large in absolute value in order to guarantee such a restricted direct impact.

\section{A Simple Numerical Example}

To illustrate the effects of tax evasion on market outcomes and constrained-optimal solutions, we subsequently present findings from a numerical example. ${ }^{12}$ To simplify computations, a linear inverse demand curve, $P(X)=10-X$, is assumed, implying that $\eta=0$ holds. The cost of evasion function, $\mathrm{T}$, is quadratic either in the product of the fraction of taxes evaded and profits, $\mathrm{T}(\alpha, \pi)=\mathrm{q}(\alpha \pi)^{2}$, or the fraction of taxes evaded, $\mathrm{T}(\alpha, 0)=\mathrm{q} \alpha^{2}$, such that $\mathrm{c}_{\mathrm{fix}}=0$. The tax rate is set equal to $20 \%(\tau=0.2)$ and the detection probability supposed to be twice as high, that is $\mathrm{q}=0.4$. These parameter values guarantee that the fraction of the tax burden evaded is strictly between 0 and $1 .{ }^{13}$ Finally, we assume unit marginal production costs $(\mathrm{c}=$ 1 ), market entry costs of one, $\mathrm{K}=1, \beta=0.5$ and neglect the integer constraint. Table 1 describes market outcomes (rows 1 to 4 ) and second-best or constrained-optimal outcomes (rows 5 to 7) for different settings. Details of the computations can be found in Appendix A.5.

\footnotetext{
${ }^{12}$ I am very grateful to an anonymous referee for suggesting this illustration of the main results of the paper.

${ }^{13}$ As profits exceed unity, as shown below, costs of evasion $\mathrm{T}(\alpha, 0)=\mathrm{q} \alpha^{2}$ are substantially lower than in the case of $\mathrm{T}(\alpha, \pi)=\mathrm{q}(\alpha \pi)^{2}$. Consequently, the fraction of taxes evaded will be noticeably higher in the former case, given the same detection probability, $\mathrm{q}$.
} 
Table 1: Numerical example: Market vs. constrained-optimal outcomes in the absence and presence of tax evasion

\begin{tabular}{|c|c|c|c|c|c|c|c|c|}
\hline & & & $\begin{array}{l}\text { Output per firm } \\
\qquad x=\sqrt{\pi}\end{array}$ & $\begin{array}{c}\text { Number } \\
\text { of firms } \\
n\end{array}$ & $\begin{array}{l}\text { Aggregate } \\
\text { output } \\
\text { X }\end{array}$ & $\begin{array}{c}\text { Fraction of tax } \\
\text { base evaded } \\
\alpha\end{array}$ & $\begin{array}{c}\text { Cost of } \\
\text { tax evasion } \\
\mathrm{T}\end{array}$ & $\begin{array}{c}\text { Welfare } \\
\text { W }\end{array}$ \\
\hline & & $\begin{array}{c}\text { Notation/ } \\
\text { Superscript }\end{array}$ & & & & & & \\
\hline & Market outcomes & & & & & & & \\
\hline 1 & No taxation & - & 1 & 8 & 8 & n. a. & n. a. & 32 \\
\hline \multirow[t]{2}{*}{4} & Evasion, $\mathrm{T}(\alpha)=\mathrm{q} \alpha^{2}$ &,+ 2 & 1.098 & 7.2 & 7.903 & 0.301 & 0.036 & 32.57 \\
\hline & Constrained-optimal outcomes & & & & & & & \\
\hline 5 & No taxation/ taxation $\&$ no evasion $(\tau=0 / \alpha=0)$ &,- opt & $\sqrt[3]{9} \approx 2.08$ & 3.327 & 6.920 & n. a. & n. a. & 35 \\
\hline
\end{tabular}

n. a. - not applicable; Specification: $\mathrm{P}(\mathrm{X})=10-\mathrm{X}, \mathrm{c}=\mathrm{K}=1, \mathrm{c}_{\mathrm{fix}}=0, \mathrm{q}=0.4, \tau=0.2, \beta=0.5$ 
First, we look at a world without taxation. The comparison of rows 1 and 5 shows that there is excessive entry in market equilibrium $(8>3.327)$ and that each firm produces a smaller quantity, $\mathrm{x}$, than is second-best optimal $(1<2.08)$. The second row in Table 1 depicts the market outcome if a profit tax of $\tau=0.2$ is imposed and actually paid. This profit tax makes entry less attractive (see Sub-section 2.3) and the number of firms drops by about $12 \%$ (from 8 to 7.05), while aggregate output falls by less than $2 \%$ because each firm raises its production. The fall in the number of competitors increases welfare, relative to the no taxation case.

Next, evasion is introduced. If the costs of tax evasion are a function of undeclared profits, $\mathrm{T}(\alpha, \pi)=\mathrm{q}(\alpha \pi)^{2}$, the entry deterrence effect of the profit tax is mitigated (row 3). The same is true if the costs of evasion depend on the fraction of the tax base evaded, $T(\alpha, 0)=q(\alpha)^{2}$ (row 4). Moreover, we show in Appendix A.5 that the number of firms, $n$, entering the market falls with q, such that a decline in the detection probability enhances tax evasion activities. These results illustrate Proposition 1.

Turning to constrained-optimal outcomes, row 6 clarifies that the welfare-maximising number of firms is greater than the optimal number in the absence of evasion if the costs of evasion are a function of undeclared profits. The relationship is reversed if the costs of evasion depend on the fraction of the tax base evaded (cf. row 7). Therefore, the comparison of rows 5 to 7 illustrates Proposition 2, that is, the constrained-optimal number of firms may rise or fall with tax evasion.

Comparing the number of firms in market equilibrium with the constrained -optimal outcome in the absence of tax evasion $(7.05-3.327=3.723)$ and in its presence if costs of evasion are given by $\mathrm{T}(\alpha, \pi)=\mathrm{q}(\alpha \pi)^{2}(7.15-3.309=3.841)$ illustrates two results: First, the number of firms in market equilibrium rises with evasion (from 7.05 to 7.15 ). Second, since the secondbest number falls (from 3.327 to 3.309), tax evasion aggravates excessive entry (cf. Proposition 3a). However, in the present example, the difference in the number of competitors in the market equilibrium and the constrained-optimal outcome actually shrinks with tax evasion from $(7.05-3.327=3.723)$ to $(7.2-3.899=3.301)$ if the costs of evasion depend on the fraction of the tax base evaded, $T(\alpha)=q \alpha^{2}$. This specification is consistent with the requirement $\mathrm{E}_{\pi}>0$ contained in Proposition $3 b$ ). Hence, the example shows that evasion may also mitigate excessive entry. 
Comparing the last columns of rows 2 to 4 clarifies that welfare will decline with tax evasion. Moreover, the decline is greater than $(1-\beta) \mathrm{T}(\alpha, \pi)$ for values of $\mathrm{n} \leq 8$, such that the fall in welfare occurs irrespective of whether $\beta=0$ or $\beta>1$ is assumed. Additionally, both cost of evasion functions considered in the example fulfil the constraint formulated in part $b$ ) of Proposition 4. Hence, the comparison of welfare in rows 2 to 5 illustrates this Proposition.

In sum, the numerical example exemplifies the claims put forward in the abstract that tax evasion raises the number of firms in market equilibrium and alters their welfare-maximizing number. Further, we have shown that tax evasion can aggravate or mitigate excessive entry.

\section{Discussion}

The number of firms entering a Cournot oligopoly may be too large from a welfare perspective if an additional competitor reduces output of each incumbent (cf. Mankiw and Whinston 1986 or Konishi et al. 1990). One possibility to internalise the business stealing externality are taxes which reduce the profitability of entry. However, taxes can be evaded. Similarly, other regulatory constraints which make market entry less attractive may be circumvented. In this paper, we focus on tax evasion and analyse how such activities with regard to a tax on operating profits affect the excess entry result. At first sight, the answer appears to be straightforward: If tax evasion raises profits, entry becomes more attractive and, hence, the non-payment of taxes encourages entry. Upon closer scrutiny, however, the relationship between tax evasion and excessive entry becomes less obvious. If tax evasion uses up resources, it will have immediate detrimental welfare consequences. Therefore, the welfare-maximising number of firms changes. The direction of this alteration depends, inter alia, on the relationship between the tax base and evasion behaviour. If a greater tax base implies that the fraction of operating profits increases which is not declared to tax authorities, the welfare-maximising number of firms can rise. In this case, tax evasion may actually mitigate the excess entry problem. However, the theoretical analysis reveals that tax evasion can also lower the welfare-maximising number of firms. Therefore, the relationship between tax evasion and market entry is more ambiguous than it may appear at first sight. The numerical example has illustrated that both situations can occur. In the specification looked at the overall welfare effects of tax evasion are negative because the gain from reducing excessive entry is not sufficient to compensate the direct, negative welfare impact of evasion.

The findings summarised above have been derived for a setting in which firms (1) are riskneutral, (2) can decide about market entry, output and tax evasion only and (3) pay a tax on 
operating profits. Consequently, the question arises whether these assumption have a decisive impact on the findings.

Risk neutrality implies that the utility gain from not paying taxes is certain. Risk aversion makes evading taxes less attractive, ceteris paribus, because of the resulting variation in income. Hence, it can be conjectured that the impact of evasion on entry will be mitigated by risk aversion. This inference may, however, be premature because the specification of welfare will change with different assumptions with regard to preferences. With respect to the second restriction it is noteworthy that the excess entry result may no longer arise if, for example, firms can decide not only about market entry and output but can, additionally, determine the cost-reducing amount of research and development (cf. Haruna and Goel 2011, Mukherjee 2012). If tax evasion continues to affect the incentives to enter the market in such a modified approach in the same way as it alters the payoffs in a world without $\mathrm{R} \& \mathrm{D}$, the evaluation of the activities considered in the present paper will basically be reversed. This is because there may be insufficient entry in the absence of tax evasion but presence of $R \& D$ investments. Moreover, allowing for another response to more intense competition, namely cost-reducing but productive activities, may in itself affect the consequences of tax evasion. This will particularly be the case if the existence of $R \& D$ costs structurally alters the gains from tax evasion. Third, we have pointed out that a tax on operating profits does not distort a firm's output choice. However, in many OECD-countries taxes on corporate income represent a much smaller fraction of tax revenues than sales taxes, taxes on inputs or social security contributions. These taxes are likely to affect the incentives to enter the market differently. The above considerations clarify that it may be insightful to look into the relationship between the incentives to enter a Cournot-oligopoly and tax evasion and, more generally, the avoidance of regulatory interventions, also in other settings. 
Appendix

\section{A.1: Impact of Higher Tax Rate}

The derivatives of equations (6), (7) and (8) with respect to the tax rate, $\tau$, are $\mathrm{A}_{\tau}=0$ and:

$$
\mathrm{B}_{\tau}=(\alpha-1)(\mathrm{P}(\mathrm{X})-\mathrm{c}) \mathrm{x}=\mathrm{E}_{\tau}(\alpha-1)<0
$$

Since, furthermore, $A_{\alpha}=B_{\alpha}=0$ holds, tax evasion does not alter the effects of a change in the tax rate on output and the number of firms, such that $\mathrm{dx}^{0} / \mathrm{d} \tau=\mathrm{dx}^{+} / \mathrm{d} \tau=\mathrm{dx} / \mathrm{d} \tau, \mathrm{dn}^{0} / \mathrm{d} \tau=$ $\mathrm{dn}^{+} / \mathrm{d} \tau=\mathrm{dn} / \mathrm{d} \tau$ and $\mathrm{dX}^{0} / \mathrm{d} \tau=\mathrm{dX} / \mathrm{d} \tau=\mathrm{dX} / \mathrm{d} \tau$. The respective derivatives are:

$$
\begin{gathered}
\frac{d x}{d \tau}=\frac{A_{n} B_{\tau}}{A_{x} B_{n}-B_{x} A_{n}}>0 \text { if } n+\eta>0 \\
\frac{d n}{d \tau}=\frac{-A_{x} B_{\tau}}{A_{x} B_{n}-B_{x} A_{n}}<0 \\
\frac{d X}{d \tau}=\frac{d x}{d \tau} n+\frac{d n}{d \tau} x=\frac{-B_{\tau} P^{\prime}(X) x}{A_{x} B_{n}-B_{X} A_{n}}<0
\end{gathered}
$$

The impact of a higher rate on tax evasion is determined by:

$$
\begin{aligned}
\frac{d \alpha}{d \tau} & =\frac{B_{\tau}\left[A_{x} E_{n}-E_{x} A_{n}\right]-E_{\tau}\left[A_{x} B_{n}-B_{x} A_{n}\right]}{D^{+}} \\
& =\frac{P^{\prime}\left(X^{+}\right) x^{+}\left(2 n^{+}+\eta\right)\left[B_{\tau} E_{x}-E_{\tau} B_{x}\right]}{n^{+}\left(n^{+}-1\right) D^{+}} \\
& =\frac{P^{\prime}\left(X^{+}\right)\left(P\left(X^{+}\right)-c\right)\left(x^{+}\right)^{2}\left(2 n^{+}+\eta\right)}{n^{+}\left(n^{+}-1\right) D^{+}}\left[E_{x}(\alpha-1)-B_{x}\right] \\
& =\underbrace{\frac{\left(P^{\prime}\left(X^{+}\right)\right)^{2}\left(P\left(X^{+}\right)-c\right)\left(x^{+}\right)^{3}\left(2 n^{+}+\eta\right)}{(-)}}_{n^{+} D^{+}}\left(T_{2}(\alpha, \pi)+(1-\alpha) T_{12}(\alpha, \pi)-1\right)
\end{aligned}
$$

Given $\mathrm{D}^{+}<0$ from (12) and $2 \mathrm{n}^{+}+\eta>0$ from the second-order condition (4), $\mathrm{d} \alpha / \mathrm{d} \tau>0$ will result if the costs of tax evasion are independent of the tax base, such that $\mathrm{T}(\alpha, \pi)=\mathrm{T}(\alpha, 0)$ and, thus, $\mathrm{T}_{2}(\alpha, \pi)=\mathrm{T}_{12}(\alpha, \pi)=0 . \mathrm{d} \alpha / \mathrm{d} \tau>0$ will also hold if higher operating profits raise the fraction of taxes evaded. This condition implies that $\mathrm{E}_{\pi}>0$ and, hence, $\tau>\mathrm{T}_{12}(\alpha, \pi)$ (cf. equation (11c)). In consequence, we have $\mathrm{T}_{2}(\alpha, \pi)+(1-\alpha) \mathrm{T}_{12}(\alpha, \pi)-1<\mathrm{T}_{2}(\alpha, \pi)+(1-\alpha) \tau$ $-1=-\left[1-(1-\alpha) \tau-\mathrm{T}_{2}(\alpha, \pi)\right]<0$. If, finally, $\mathrm{E}_{\pi}<0, \mathrm{~d} \alpha / \mathrm{d} \tau>0$ will hold if, additionally, $0<$ $\mathrm{T}_{2}(\alpha, \pi)+(1-\alpha) \mathrm{T}_{12}(\alpha, \pi)$ is not too large in absolute value.

If the cost of evasion function increases with the tax rate as well $(\partial \mathrm{T} / \partial \tau>0), \mathrm{B}_{\tau}$ continues to be negative. Therefore, $E_{\tau} \geq 0$ is a sufficient condition for $d \alpha / d \tau>0$, given $E_{X}<0$. In the case of $\mathrm{E}_{\mathrm{X}}>0, \mathrm{E}_{\tau}>0$ becomes a necessary condition for $\mathrm{d} \alpha / \mathrm{d} \tau>0$. 


\section{A.2: Proof of Proposition 1}

Using $\mathrm{A}_{\mathrm{q}}=0, \mathrm{~B}_{\mathrm{q}}=-\mathrm{S}(\alpha, \pi)<0, \mathrm{E}_{\mathrm{q}}=-\mathrm{S}_{1}(\alpha, \pi)<0$, and given $\mathrm{T}_{1}(\alpha, \pi)=\mathrm{qS}_{1}(\alpha, \pi)$, the impact of the detection probability $q$ on the optimal fraction, $\alpha$, of the tax burden evaded, is:

$$
\begin{aligned}
\frac{d \alpha}{d q}= & \frac{B_{q}\left[A_{x} E_{n}-E_{x} A_{n}\right]-E_{q}\left[A_{x} B_{n}-B_{x} A_{n}\right]}{D^{+}} \\
= & \frac{P^{\prime}\left(X^{+}\right) x^{+}\left(2 n^{+}+\eta\right)}{n^{+}\left(n^{+}-1\right) D^{+}}\left(B_{q} E_{x}-E_{q} B_{x}\right) \\
= & \frac{\left(P^{\prime}\left(X^{+}\right)\right)^{2}\left(x^{+}\right)^{2}\left(2 n^{+}+\eta\right)}{n^{+} D^{+}} \\
& \quad \times\{S_{1}(\alpha, \pi) \underbrace{\left(1-\tau(1-\alpha)-T_{2}(\alpha, \pi)\right)}_{(+)}-S(\alpha, \pi) \underbrace{\left(\tau-T_{12}(\alpha, \pi)\right)}_{=E_{\pi}}\}
\end{aligned}
$$

Tax evasion will increase with a decline in $\mathrm{q}$ if the term in curly brackets is positive, since $\mathrm{D}^{+}$ $<0$. This will obviously be the case if higher operating profits decrease the fraction of taxes evaded, $\alpha$, ceteris paribus, i.e. if $\mathrm{E}_{\pi}=\tau-\mathrm{T}_{12}(\alpha, \pi)<0$. Moreover, the last line of (A.7) will be positive if the costs of tax evasion are independent of the tax base, i. e. if $T=T(\alpha, 0)$ and $\mathrm{T}_{2}(\alpha, \pi)=\mathrm{T}_{12}(\alpha, \pi)=0$ holds. In this case, the term in curly brackets in (A.7) can be rewritten as $(1-\tau) S_{1}(\alpha, 0)+\tau\left(S_{1}(\alpha, 0) \alpha-S(\alpha, 0)\right)$, which is greater than zero because $S_{1}$, $\mathrm{S}_{11}>0$ and $\mathrm{S}(0,0)=0$.

The number of firms characterising the market equilibrium rises with a fall in q.

$$
\frac{\mathrm{dn}^{+}}{\mathrm{dq}}=-\frac{\mathrm{E}_{\alpha} \mathrm{A}_{\mathrm{x}} \mathrm{B}_{\mathrm{q}}}{\mathrm{D}^{+}}<0
$$

Consequently, if a fall in q increases the fraction of the tax burden evaded $(\mathrm{d} \alpha / \mathrm{dq}<0)$, the number of firms will rise. This proves Proposition 1.

\section{A.3: Proof of Proposition 2}

Part a) of the Proposition is obvious from inspection of equation (18).

Note that $\eta+2 n \geq 1+n+\eta$ will hold for $n \geq 1$. If $\beta<1$, the derivative in (18) will, hence, be positive if the term in curly brackets in its last line is greater in absolute value than the positive first summand, $\mathrm{T}(\alpha, \pi)$. The conditions enlisted in part $b$ ) of Proposition 2 imply that the second- and third summands in curly brackets are zero because $\mathrm{T}(\alpha, \pi)=\mathrm{T}(\alpha, 0)$ implies that $\mathrm{T}_{2}(\alpha, 0)=\mathrm{T}_{12}(\alpha, 0)=0$. If the costs of tax evasion are given by a second- or higherorder polynomial, they may be expressed as $\mathrm{T}(\alpha, 0)=\mathrm{q} \alpha \mathrm{m}+\mathrm{c}_{\text {fix }}$, where $\mathrm{m} \geq 2$. Hence, $\mathrm{T}(\alpha$,

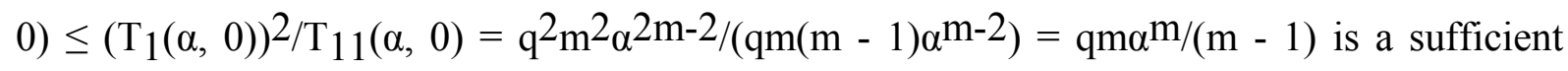
condition for the derivative in (18) to be positive. The inequality $\mathrm{q}^{\mathrm{m}} \mathrm{m}+\mathrm{c}_{\mathrm{fix}} \leq \mathrm{qm} \alpha \mathrm{m} /(\mathrm{m}-1)$ 
will be fulfilled if $(\mathrm{m}-1) \mathrm{c}_{\mathrm{fix}} \leq \mathrm{q} \alpha \mathrm{m}$, i.e., if the fixed costs of tax evasion are zero or not too high. This proves part $b$ ) of the Proposition.

If $\mathrm{T}(\alpha, \pi)=\mathrm{T}(\alpha \pi)$ holds, $\mathrm{T}_{1}(\alpha \pi)=\mathrm{T}^{\prime} \pi, \mathrm{T}_{11}(\alpha \pi)=\mathrm{T}^{\prime} \pi^{2}$, and $\mathrm{T}_{2}(\alpha \pi)=\mathrm{T}^{\prime} \alpha$. Equation (8) is given by $\mathrm{E}=\tau \pi-\mathrm{T}_{1}(\alpha \pi)=\tau \pi-\mathrm{T}^{\prime} \pi=0$, such that $\mathrm{E}_{\pi}=-\mathrm{T}^{\prime} \alpha \pi$. Replacing $\mathrm{T}_{1}, \mathrm{~T}_{11}, \mathrm{~T}_{2}$ and $\mathrm{E}_{\pi}$ in the second line of (18) shows that the term in curly bracket is zero. This proves part $\mathrm{c}$ ).

\section{Appendix A.4: Proof of Proposition 4}

Employing (A.7), (A.8), (13), and $\partial n / \partial q=-(\partial x / \partial q)\left(A_{X} / A_{n}\right)$, the impact of a rise in the parameter q can be calculated as:

$$
\begin{aligned}
& \frac{d W^{+}}{d q}=\frac{\partial W^{+}}{\partial n} \frac{\partial n}{\partial q}+\frac{\partial W^{+}}{\partial x} \frac{\partial x}{\partial q}+\frac{\partial W^{+}}{\partial \alpha} \frac{\partial \alpha}{\partial q}+\frac{\partial W^{+}}{\partial q} \\
& =\frac{\partial W^{+}}{\partial n} \frac{-A_{x} B_{q}}{A_{x} B_{n}-A_{n} B_{x}}+\frac{\partial W^{+}}{\partial x} \frac{A_{n} B_{q}}{A_{x} B_{n}-A_{n} B_{x}} \\
& -\frac{\partial W^{+}}{\partial \alpha} \frac{\left(A_{n} E_{x}-A_{x} E_{n}\right) B_{q}}{E_{\alpha}\left(A_{x} B_{n}-A_{n} B_{x}\right)}-\frac{\partial W^{+}}{\partial \alpha} \frac{E_{q}}{E_{\alpha}}+\frac{\partial W^{+}}{\partial q} \\
& =\frac{-A_{x} B_{q}}{A_{x} B_{n}-A_{n} B_{x}}\left[\frac{\partial W^{+}}{\partial n}-\frac{\partial W^{+}}{\partial x} \frac{A_{n}}{A_{x}}+\frac{\partial W^{+}}{\partial \alpha} \frac{A_{n} E_{x}-A_{x} E_{n}}{E_{\alpha} A_{x}}\right]-\frac{\partial W^{+}}{\partial \alpha} \frac{E_{q}}{E_{\alpha}}+\frac{\partial W^{+}}{\partial q} \\
& =\underbrace{\frac{n^{+}\left(1+n^{+}+\eta\right) S(\alpha, \pi)}{(1-\tau(1-\alpha)) P^{\prime}\left(X^{+}\right)\left(x^{+}\right)^{2}\left(2 n^{+}+\eta\right)}}_{<0} \frac{d W^{+}}{d n}+(1-\beta) n^{+}\left[\frac{\left(S_{1}(\alpha, \pi)\right)^{2}}{S_{11}(\alpha, \pi)}-S(\alpha, \pi)\right]
\end{aligned}
$$

Hence, welfare rises with a decline in the parameter q, i.e. the derivative in (A.12) is negative if, for example, $\mathrm{dW}^{+} / \mathrm{dn}>0$ and $\beta=1$ hold. This establishes part a). Assuming $\beta<1$, the derivative in (A.12) is positive if $\mathrm{dW}^{+} / \mathrm{dn}<0$ and $\left(\mathrm{S}_{1}(\alpha, \pi)\right)^{2} / \mathrm{S}_{11}(\alpha, \pi)-\mathrm{S}(\alpha, \pi)>0$ apply. The inequality $\left(\mathrm{S}_{1}(\alpha, \pi)\right)^{2} / \mathrm{S}_{11}(\alpha, \pi)-\mathrm{S}(\alpha, \pi)>0$ holds if $\mathrm{T}(\alpha, \pi)=\mathrm{T}(\alpha, 0)$ or $\mathrm{T}(\alpha, \pi)=\mathrm{T}(\alpha \pi)$, and $\mathrm{T}(\alpha, \pi)$ is given by a second- or higher-order polynomial. For $\mathrm{T}(\alpha, \pi)=(\alpha \pi)^{\mathrm{m}}+\mathrm{c}_{\mathrm{fix}}$, where $\mathrm{m} \geq 2,\left(\mathrm{~S}_{1}(\alpha, \pi)\right)^{2} / \mathrm{S}_{11}(\alpha, \pi)-\mathrm{S}(\alpha, \pi)=(\alpha \pi)^{\mathrm{m}} /(\mathrm{m}-1)>0$ results such that the restriction is fulfilled. If the costs of evasion are a function of the fraction of taxes evaded, such that $\mathrm{T}(\alpha, 0)=\alpha^{\mathrm{m}}+\mathrm{c}_{\text {fix }}$, we have $\left(\mathrm{S}_{1}(\alpha, 0)\right)^{2} / \mathrm{S}_{11}(\alpha, 0)-\mathrm{S}(\alpha, 0)=\alpha \mathrm{m} /(\mathrm{m}-1)>0$.

\section{Appendix A.5: Numerical Example}

We denote market outcomes in the absence of taxation with the superscript '-', in the presence of taxes but absence of evasion by ' 0 ' and in the presence of tax evasion by ' + '. Constrained- 
optimal solutions are indexed with the additional superscript 'opt'. Further, we set $\mathrm{c}=\mathrm{K}=1, \tau$ $=0.2, \mathrm{q}=0.4, \mathrm{c}_{\mathrm{fix}}=0$, and $\mathrm{P}(\mathrm{X})=10-\mathrm{X}$.

Market outcome in the absence of taxation (Table 1, row 1)

The market outcome in the absence of taxes is, setting $\tau=0$, determined by equations $\left(6^{\prime}\right)$ and (7) and, thus, by $P-X-x-c=9-X-x=0$ and $(9-X) x=1$. Combining both equalities yields $\mathrm{X}^{-}=1, \mathrm{n}^{-}=\mathrm{X}^{-}=8$ and $\mathrm{W}^{-}=(10-\mathrm{P}(\mathrm{X})) \mathrm{X} / 2+(\mathrm{P}(\mathrm{X})-\mathrm{c}) \mathrm{X}-\mathrm{n}=\mathrm{X}^{2} / 2+\mathrm{X}-\mathrm{n}=32$.

Market outcome in the presence of taxation but without evasion (Table 1, row 2)

We next turn to a world with taxes but without evasion. Following the same approach as above, that is, using $9-\mathrm{X}=\mathrm{x}$ and $(1-\tau)(9-\mathrm{X}) \mathrm{x}=1$, taxation can be shown to reduce the number of firms in market equilibrium to $\mathrm{n}^{0} \approx 7.05$, while output per firm increases to $\mathrm{x}^{0} \approx$ 1.118 , resulting in an aggregate output of $\mathrm{X}^{0} \approx 7.882$ and a welfare level of $\mathrm{W}^{0} \approx 32.82$.

Market outcome in the presence of taxation and evasion (Table 1, rows $3 \& 4$ )

Initially, we assume that the costs of tax evasion are a function of the product of profits and the share of the tax burden evaded, namely $\alpha \pi$. To ensure that restrictions on the functional form for $\mathrm{T}$ imposed in Sub-section 2.1 hold, we specify $\mathrm{T}$ as $\mathrm{T}(\alpha, \pi)=\mathrm{q}(\alpha \pi)^{2}$. This assumption implies that $\mathrm{E}_{\pi}=\tau-\mathrm{T}_{12}(\alpha, \pi)=\tau-4 \mathrm{q} \alpha \pi$. As an alternative, we consider $\mathrm{T}(\alpha)=$ $\mathrm{q} \alpha^{2}$, resulting in $\mathrm{E}_{\pi}=\tau>0$. Outcomes in a setting in which $\mathrm{T}(\alpha, \pi)=\mathrm{q}(\alpha \pi)^{2}\left[\mathrm{~T}(\alpha, 0)=\mathrm{q} \alpha^{2}\right]$ holds are subsequently denoted by the additional superscript 1 [2]. This way of differentiating results is used for market and constrained-optimal outcomes.

Given $\mathrm{T}^{+}, 1=\mathrm{q}(\alpha \pi)^{2}$, the first-order condition for the optimal choice of $\alpha$ (cf. equation (8)) yields $\alpha \pi=\tau /(2 q)=1 /(10 q)=0.25$. Hence, the costs of tax evasion are constant and equal $\mathrm{T}^{+}, 1=\mathrm{q}(\alpha \pi)^{2}=0.025$. Using this information, it is possible to solve the zero-profit condition (6) to obtain $\alpha^{+}, 1=8 /(100 q-1) \approx 0.205$. Since $\pi=x^{2}$ from (13a) and using the definition of $\pi$ we, furthermore, find $x^{2}=1 /(10 \alpha q)=(100 q-1) /(80 q)$, such that $x$ rises in $q$, while $n=9 / x$ -1 declines in the detection probability, $\mathrm{q}$ (see Proposition 1 ). Solving for $\mathrm{x}$, we obtain $\mathrm{x}^{+}, 1 \approx$ 1.104. Inserting this value into $\mathrm{n}=9 / \mathrm{x}-1$ yields $\mathrm{n}^{+, 1} \approx 7.15$, such that $\mathrm{X}^{+}, 1 \approx 7.896$. Furthermore, welfare can be computed as $\mathrm{W}^{+}, 1 \approx 32.65$.

Under the alternative assumption of $\mathrm{T}^{+, 2}=\mathrm{q} \alpha^{2}$, the firm's optimal evasion choice (cf. equation (8)) results in $\pi=10 \mathrm{q} \alpha$. Using this information in the zero-profit constraint allows for the derivation of the optimal evasion decision, which is given by $\alpha^{+, 2}=\sqrt{16+1 / q}-$ $4 \approx 0.301$. This implies $\mathrm{T}^{+}, 2 \approx 0.036$. Combining $\pi=\mathrm{x}^{2}$ from (13a) and $\pi=10 \mathrm{q} \alpha$ yields $\mathrm{x}^{+}, 2 \approx 1.098$ and $\mathrm{n}^{+, 2} \approx 7.2$, such that $\mathrm{X}^{+, 2} \approx 7.903$. Note that an increase in q reduces $\alpha$ and raises profits, $\pi=10 \mathrm{q} \alpha(\mathrm{q})$, and hence, output per firm, $\mathrm{x}$. This, in turn, implies that the number of firms - which declines in output per firm - becomes smaller if tax evasion is 
reduced. Conversely, a decline in $\mathrm{q}$ implies a rise in the number of entrants (see Proposition 1). Finally, welfare can be computed as $\mathrm{W}^{+}, 2 \approx 32.57$.

Second-best outcome in the absence of tax evasion (Table 1, row 5)

The second-best outcomes are the same in settings in which firms either determine output while there are either no taxes or, alternatively, taxes cannot be evaded because taxation has no impact on the firm's output choice. Hence, $9-\mathrm{X}-\mathrm{x}=0$ holds. The second-best outcome results from the maximization of welfare, $\mathrm{W}$, subject to the adjustment in output to the number of firms. Combining (15) and (13a) yields:

$$
\frac{\mathrm{dW}}{\mathrm{dn}}=(\mathrm{P}(\mathrm{X})-\mathrm{c}) \frac{\mathrm{x}}{1+\mathrm{n}}-1=(9-\mathrm{X}) \frac{\mathrm{x}}{1+\mathrm{n}}-1=0
$$

Substituting, for example, $\mathrm{X}=\mathrm{xn}$ into this equation and into $9-\mathrm{X}=\mathrm{x}$ and solving the system, we obtain $\mathrm{x}^{0, \mathrm{opt}}=9^{1 / 3} \approx 2.08, \mathrm{n}^{0, \mathrm{opt}} \approx 3.327, \mathrm{X}^{0, \mathrm{opt}}=6.92, \pi^{0, \mathrm{opt}}=4.32$ and $\mathrm{W}^{0}, \mathrm{opt} \approx 35$.

Second-best outcome in the presence of tax evasion (Table 1, rows $6 \& 7$ )

Using equation (13a), the constrained optimum can be defined as:

$$
\frac{d W}{d n}=(P(X)-c) \frac{x}{1+n}-K-(1-\beta)\left[T(\alpha, \pi)+\mathrm{nT}_{1} \frac{d \alpha}{d n}+\mathrm{nT}_{2} \frac{d \pi}{d n}\right]=0
$$

Assuming $\mathrm{T}^{+}, 1=\mathrm{q}(\alpha \pi)^{2}$, using the specific values employed for the numerical example, and also taking into account (13b) and (13c), (A.14) can be rewritten as:

$$
\frac{d W}{d n}=(9-X) \frac{x}{1+n}-1-(1-\beta) q\left[\alpha^{2} \pi^{2}-n \alpha \frac{E_{\pi} x^{2}}{q(1+n)}-n \alpha^{2} \pi \frac{x^{2} 2}{(1+n)}\right]=0
$$

Using the definition of $E_{\pi}$ (cf. equation (11b)) and $\alpha \pi=\tau /(2 q)$ from (8) clarifies that last two terms in square brackets sum to zero. Replacing $\alpha \pi$ by $\tau /(2 q)=0.25$ and $(9-X) x=\pi=x^{2}$, we can solve (A.15) for $n$.

$$
\mathrm{n}=\frac{\mathrm{x}^{2}-(1+0.025(1-\beta))}{1+0.025(1-\beta)}
$$

Combining this expression with the first-order condition for the firm's output choice and replacing $\beta$ by 0.5 , we obtain:

$$
\frac{x^{2}-1.0125}{1.0125}=\frac{9-x}{x}
$$

Solving this equation yields $x^{+, 1, o p t}=\sqrt[3]{9.1125} \approx 2.089$. From this output level per firm, we can calculate $\mathrm{n}^{+}, 1$,opt $\approx 3.309, \mathrm{X}^{+}, 1$,opt $\approx 6.912$ and $\pi^{+}, 1$,opt $\approx 4.36$. Given $\alpha \pi=0.25$, the fraction of the tax base evaded equals $\alpha^{+}, 1$,opt $=1 /(4 \pi) \approx 0.057$. Welfare can, using the standard approach outlined above, be computed as $\mathrm{W}^{+}, 1$,opt $\approx 34.97$. 
Finally, we calculate $\mathrm{dW} / \mathrm{dn}=0$ for $\mathrm{T}^{+}, 2=\mathrm{q} \alpha^{2}$. This derivative is given by:

$$
\frac{\mathrm{dW}}{\mathrm{dn}}=(9-\mathrm{X}) \frac{\mathrm{x}}{1+\mathrm{n}}-1-0.5\left[q \alpha^{2}-\mathrm{n} 2 \mathrm{q} \alpha \frac{\tau 2 \mathrm{nx} \mathrm{x}^{2}}{2 \mathrm{qn}(1+\mathrm{n})}\right]=0
$$

Since $\pi=(9-X) x=x^{2}$ and $\alpha=\tau x^{2} /(2 q)$ from (8) and $\pi=x^{2}$, we obtain:

$$
\frac{\mathrm{dW}}{\mathrm{dn}}=\frac{\mathrm{x}^{2}}{1+\mathrm{n}}-1-0.125 \frac{\tau^{2} \mathrm{x}^{4}}{\mathrm{q}} \frac{1-3 \mathrm{n}}{1+\mathrm{n}}=0
$$

Solving this expression for $\mathrm{n}$, yields:

$$
\mathrm{n}=\frac{8 \mathrm{qx} \mathrm{x}^{2}-8 \mathrm{q}-\tau^{2} \mathrm{x}^{4}}{8 \mathrm{q}-3 \tau^{2} \mathrm{x}^{4}}
$$

Combining (A.20) and $\mathrm{n}=(9-\mathrm{X}) \mathrm{x}$, and substituting for $\mathrm{q}$ and $\tau$, we obtain a fifth-order polynomial.

$$
0=28.8-3.2 x^{3}-1.08 x^{4}+0.16 x^{5}
$$

Solving this expression for $\mathrm{x}$, we obtain $\mathrm{x}^{+, 2, \mathrm{opt}} \approx 1.837$. Further solutions to (A.21) lie outside the range $0<\mathrm{x}<4.5$. Since $\mathrm{x}>4.5$ implies that $\mathrm{n}<1$, we can ignore such solutions. Accordingly, the constrained-optimal number of firms equals $\mathrm{n}^{+}, 2, \mathrm{opt} \approx 3.899$, and aggregate output and profits are given by $\mathrm{X}^{+}, 2$,opt $\approx 7.164$ and $\pi^{+}, 2$,opt $\approx 3.37$. The fraction of taxes evaded is $\alpha^{+}, 2$,opt $\approx 0.844$. Finally, welfare equals $\mathrm{W}^{+}, 2$,opt $\approx 34.36$. 
Amir, Rabah and Chrystie Burr (2015), Corruption and Socially Optimal Entry, Journal of Public Economics 123, 30-41.

Amir, Rabah, De Castro, Luciano and Leonidas Koutsougeras (2014), Free Entry versus Socially Optimal Entry, Journal of Economic Theory 154, 112-125.

Becker, Gary S. (1968), Crime and Punishment: An Economic Approach, Journal of Political Economy 76(2), 169-217.

Besfamille, Martin, De Donder Philippe and Jean Marie Lozachmeur (2009), Tax Enforcement may Decrease Government Revenue, Economics Bulletin 29, Iss. 4, $2665-$ 2672.

Besfamille, Martin, De Donder Philippe and Jean Marie Lozachmeur (2013), The Political Economy of the (Weak) Tax Enforcement of Indirect Taxes, Journal of Public Economic Theory 15(6), 856-883.

Besley, Timothy (1989), Commodity Taxation and Imperfect Competition - A Note on the Effects of Entry, Journal of Public Economics 40(3), 359-365.

Bundestag (2016), $4^{\text {th }}$ Committee of Inquiry in the $18^{\text {th }}$ Electoral Period (see: https://www. bundestag.de/ bundestag/ausschuesse18/ua/4untersuchungsausschuss; in German)

European Commission (2016), Proposal for a Council Directive Laying Down the Rules Against Tax Avoidance Practices that Directly Affect the Functioning of the Common Market, $\operatorname{COM}(2016) 26$ final.

Cremer, Helmuth and Firouz Gahvari (1993), Tax Evasion and Optimal Commodity Taxation, Journal of Public Economics 50(2), 261-275.

Delipalla, Sophia and Michael Keen (1992), The Comparison between Ad Valorem and Specific Taxation under Imperfect Competition, Journal of Public Economics 49(3), 351367.

Goerke, Laszlo (2012), The Optimal Structure of Commodity Taxation in a Monopoly with Tax Avoidance or Evasion, Public Finance Review 40(4), 519-536.

Goerke, Laszlo and Marco Runkel (2006), Profit Tax Evasion under Oligopoly with Endogenous Market Structure, National Tax Journal 59(4), 851-857.

Goerke, Laszlo and Marco Runkel (2011), Tax Evasion and Competition, Scottish Journal of Political Economy 58(5), 711-736.

Grubert, Harry and Joel Slemrod (1998), The Effect of Taxes on Investment and Income Shifting to Puerto Rico. The Review of Economics and Statistics 80(3), 365-373.

Hamilton, Stephen F. (1999), Tax Incidence Under Oligopoly: A Comparison of Policy Approaches, Journal of Public Economics 71(2), 233-245.

Haruna, Shoji and Rajeev K. Goel (2011), R\&D, Free Entry, and Social Inefficiency, Economics of Innovation and New Technology 20(1-2), 89-101.

Konishi, Hideki, Okuno-Fujiwara, Masahiro and Kotaro Suzumura (1990), Oligopolistic Competition and Economic Welfare: A General Equilibrium Analysis of Entry Regulation and Tax-Subsidy Schemes, Journal of Public Economics 42(1), 67-88.

Mankiw, N. Gregory and Michael D. Whinston (1986), Free Entry and Social Inefficiency, The Rand Journal of Economics 17(1), 48-58.

Mukherjee, Arijit (2012), Endogenous Cost Asymmetry and Insufficient Entry in the Absence of Scale Economies, Journal of Economics 106(1), 75-82. 
Ohkawa, Takao and Makoto Okamura (2003), On the Uniqueness of the Welfare-maximizing Number of Firms under Cournot-Oligopoly, Bulletin of Economic Research 55(2), 209222.

Perry, Martin K. (194), Scale Economies, Imperfect Competition, and Public Policy, The Journal of Industrial Economics 32(3), 313-333.

Roine, Jesper (2006), The Political Economics of Not Paying Taxes, Public Choice 126(1-2), 107-134.

Seade, Jesus (1980), On the Effects of Entry, Econometrica 48(2), 479-489.

Seidel, André and Marcel Thum (2016), Tax Evasion, Corruption and Market Entry, Scottish Journal of Political Economy (forthcoming).

Slemrod, Joel (2001), A General Model of the Behavioral Response to Taxation, International Tax and Public Finance 8(2), 119-128.

Stern, Nicholas (1987), The Effects of Taxation, Price Control and Government Contracts in Oligopoly and Monopolistic Competition, Journal of Public Economics 32, 133-158.

Suzumura, Kotaro (1995), Competition, Commitment, and Welfare, Clarendon Press: Oxford.

Suzumura, Kotaro and Kazuharu Kiyono (1987), Entry Barriers and Economic Welfare, Review of Economic Studies 54(1), 157-167.

Traxler, Christian (2009), Voting over Taxes: The Case of Tax Evasion, Public Choice 140(1), 43-58.

Varian, Hal (1995), Entry and Cost Reduction, Japan and the World Economy 7(4), 399-410.

von Weizsäcker, Carl Christian (1980), A Welfare Analysis of Barriers to Entry, Bell Journal of Economics 11(2), 399-420.

Yaniv, Gideon (1995), A Note on the Tax Evading Firm, National Tax Journal 48(1), 113 120. 